Check for updates

The BMJ

Cite this as: BMJ 2021;373:n1072 http://dx.doi.org/10.1136/bmi.n1072 Published: 23 April 2021

\title{
Covid-19: One in five government contracts had signs of possible corruption, report finds
}

Gareth lacobucci

A fifth of UK government contracts awarded to respond to the covid-19 pandemic last year contained red flag indicators of possible corruption, a report has concluded. ${ }^{1}$

The campaign group Transparency International UK identified 73 "questionable contracts" worth more than $€ 3.7 \mathrm{bn}$ ( $€ 4.3 \mathrm{bn}$; \$5.1bn) in total that warranted further investigation. Most of these (65), worth $£ 2.9 \mathrm{bn}$, were for personal protective equipment.

By value, the 73 contracts accounted for $20 \%$ of all reported contracting for the UK's covid-19 response between February and the end of November 2020. All 73 should now be subject to "detailed audits by relevant authorities,” the report said.

The report criticised the arrangement put in place by the Cabinet Office and the Department of Health and Social Care for England that allowed some companies bidding for contracts to be channelled through a so called "VIP" or "high priority" lane because of their political connections.

"Adopting such an approach adds credence to the view that cronyism determined the award of contracts, rather than suitability for the job," it said. "This approach has undoubtedly damaged trust in the integrity of the pandemic response."

The group identified 30 contracts awarded to companies with connections to the Conservative Party, including 24 PPE contracts worth £1.6bn, three testing contracts worth $£ 536 \mathrm{~m}$, and a three worth $£ 4.1 \mathrm{~m}$ for other services.

It noted that details for $93 \%$ ( 28 of 30 ) were published late, which compares with $70 \%$ of contracts (688 of 970) awarded to companies that didn't have political connections. "Given the context of these procurements, significant delays to their disclosure-whether intentionally or otherwise-gives the impression that there is something to hide," it said.

The National Audit Office previously raised concerns about the VIP lane system in a report published last November, ${ }^{2}$ after finding that suppliers referred to it were 10 times as likely to be awarded a contract as those that came through the ordinary lane.

The government has said that it established the VIP lane as a triage system to assess potential PPE sources that were deemed most credible in the face of huge global demand.

But Transparency International UK identified £255m worth of contracts that went to 10 firms that were less than 60 days old. It said this raised "valid questions as to why these were treated as more qualified for the job, especially given the reported availability of other more established companies."

The public sector should be undertaking competitive procurement "as a default," the report recommended.

Meanwhile, emails made public this week after legal action by the Good Law Project show that civil servants were "drowning" in offers of PPE from firms in the VIP lane last year, which delayed efforts to buy PPE from other suppliers. ${ }^{3}$

One email from an official handling an offer to supply PPE to the NHS warned that when VIPs "jump to the front of the queue it then has a knock on effect to the remaining offers of help." ${ }^{4}$ Another email shows a civil servant questioning the standard of PPE supplied by a company called Ayanda Capital that came through the VIP lane. "The bar seems to have been lowered on this one," they wrote. ${ }^{5}$

Rachel Reeves, the shadow Cabinet Office minister, said, "It is shocking that basic checks were missed and companies without proper certification were allowed to jump the queue. Time and time again, Labour has called on the Conservatives to publish details of companies on the VIP fast lane, and time and time again they have refused and insisted on covering them up.”

A government spokesperson said, "During the pandemic our priority has always been to protect the public and save lives, and we have used existing rules to buy lifesaving equipment and supplies, such as PPE for the NHS front line.

"All PPE procurement went through the same assurance process, and due diligence is carried out on every contract-ministers have no role in awarding them.

"The priority list was widely advertised across government as a way of more quickly triaging offers of support."

Transparency International UK. Track and trace: Identifying corruption risks in UK public procurement for the covid-19 pandemic. Apr 2021. https://www.transparency.org.uk/sites/default/files/pdf/publications/Track\%20and\%20Trace\%20-\%20Transparency\%20International\%20UK.pdf.

2 lacobucci G. Covid-19: Government has spent billions on contracts with little transparency, watchdog says. BMJ2020;371:m4474. doi: 10.1136/bmi.m4474 pmid: 33208349

3 Good Law Project. Explosive emails show how the Government's VIP lane caused chaos in PPE procurement. 22 Apr 2021. https://goodlawproject.org/news/ppe-urgent-hearing. https://drive.google.com/file/d/1x5qdjuwL56idKvhc06pvcSL5e0CLeLJ9/view.

https://drive.google.com/file/d/1wfaSkwJCnxpL_8x8YdnsEb844vDZOkV/view. 